\title{
The Livelihood Improvement Process: An Inclusive and Pro- Poor Approach to Community Forestry - Experiences from Kabhrepalanchok and Sindhupalchok Districts of Nepal
}

\author{
Murari Joshi ${ }^{*}$, Lokendra Dhakal ${ }^{*}$, Gopi Paudel ${ }^{*}$, Raghu Shrestha*, Arun Paudel ${ }^{*}$ Padam \\ Bahadur Chand ${ }^{*}$ and Netra Prasad Timsina\# \\ ${ }^{*}$ Nepal Australia Community Resource and Livelihood Management Project \\ Email: nacrlmp@wlink.com.np \\ \#ForestAction Nepal
}

\begin{abstract}
Reducing poverty through equitable and sustainable community-based natural resource management, particularly through programmes that accord attention to the issue of social inclusion, is the major objective of development projects related to natural resource management. At the local level, many innovations have been developed and are being put in place to enhance the pro-poor approaches, which specifically focus on the issues of livelihoods and inclusion. Livelihood Improvement Process (LIP) is one of the innovations arising to address this end. This paper presents the concept, process of implementation, and impacts of the LIP, as well as the opportunities and challenges it faces based on the experiences gained in Kabhrepalanchok and Sindhupalchok districts of Nepal. It concludes that the LIP can be an appropriate tool for reaching the poor, as it helps to sensitise and inform all actors about the need of pro-poor and inclusive development process.
\end{abstract}

Key Words: community forestry, livelihood improvement process, social inclusion, governance

\section{INTRODUCTION}

Sustainable forest management, livelihoods and good governance-all termed "secondgeneration issues" - are the major issues that Community Forestry (CF) now addresses. Governance has to be improved for two reasons: first, to make sure that the voice of the different groups of people particularly the poor and excluded are heard; second, to enhance the economic and social welfare of the people through the sustainable management of forest resources (Pokharel, 2001; Timsina et al., 2004). In particular, the number and diversity of forest-based business enterprises which offer Community Forest User Groups (CFUGs) members opportunities for income generation and livelihood enhancement need to expand. The very small allocation (3\% of total expenditures) of the total income of CFUGs to pro-poor activities also need to increase (Kanel 2004; NACRMLP 2004).

In the forestry sector, the major focus of the Tenth Plan (2002-2007) is to support the national objective of poverty alleviation by ensuring that people participate in sustainable forestry development efforts, including the management of forest, plant and herb resources; watershed management; bio-diversity conservation; and increasing employment opportunities, especially for the poor, women and otherwise marginalized sections of society, through the development of forest-based industries (HMGN, 2002). It encompasses both Nepal's Millennium Development Goals (MDGs) and it's Poverty Reduction Strategy Paper (PRSP). The latter has one main objective: reducing poverty from 38 to 30 percent within the Plan period using four pillars of intervention - broad-based high economic growth, social sector development, social inclusion and targeted programmes, and good governance. The Forestry Sector Coordination Committee (FSCC) of the Ministry of Forest and Soil Conservation (MFSC) has identified three themes that need to be improved: livelihoods, governance and sustainable forest management (Kanel, 2004).

The exclusionary social system in Nepal poses a serious challenge to achieving equity and justice in development programmes. The social barriers to inclusion in Nepal include gender, caste, ethnicity, language, religion, and geo-politics. "Social inclusion" is understood to mean a complementary approach that seeks to bring about system- 
level institutional reforms and policy changes. In the words of a 2005 report published by DFID and the World Bank, "Social inclusion requires a shift from an institutional environment which gives some people more opportunity to realise their agency than others, to one where the political system and laws support equal agency for all" (DFID/WB, 2005). This report suggests that historically-rooted institutions and polices have been the principal barriers to social inclusion. This is also true in the case of Community Forestry, as CFUGs tend to be dominated by the local elites and to exclude dalits, women, ethnic groups and the poor. The Federation of Community Forest Users Nepal (FECOFUN), various NGOs, and a number of bilateral forestry projects, such as the Livelihood and Forestry Programme funded by DFID, the Nepal Swiss Community Forestry Project funded by SDC and the Nepal-Australia Community Resource and Livelihood Project (NACRMLP) funded by AusAid, have developed pro-poor and inclusive processes for use in the
Community Forestry Programme. While many projects and NGOs and, to some extent, the government have tried out new strategies to include the marginalised in the $\mathrm{CF}$ process and improve the livelihoods of these populations; these innovations now need to be mainstreamed within Nepal's forestry policies and strategies.

This article is based on the experiences of NACRMLP, a bilateral forestry project being implemented in Kavrepalanchok and Sindhupalchok districts of Nepal. It focuses on improving the livelihoods of the forestdependent poor in an effort to address the second-generation issues described above. It works to mainstream a pro-poor and inclusive approach in forestry institutions at all levels. In particular, the project, through local service providers, facilitates a Livelihood Improvement Process (LIP) at the local level with CFUGs. To this end, this paper describes and analyses this innovation carried out so far.

\section{WHAT IS THE LIVELIHOOD IMPROVEMENT PROCESS?}

The LIP is a tool for promoting holistic, propoor, socially and gender-inclusive community development processes within CFUGs. The LIP aims to enhance the wellbeing of all $\mathrm{CF}$ users particularly that of poor and disadvantaged groups, as well as to improve governance at the local level by mobilising community-based resources.

The outcome of the LIP process is a plan prepared by a CFUG with the active participation of all of its diverse members, including the poor, women, and disadvantaged groups as well as the elite. Local facilitators trained in the concepts and processes of participatory LIP approach. Government organisations, specifically the District Forest Office (DFO), and other service providers provide back-up support.

The LIP lays out the policies and processes for implementing a holistic community development programme. It includes provisions for providing special support to poor and disadvantaged members as well as guidelines for institutional development.

\section{LIVELIHOOD IMPORVEMENT PROCESS DEVELOPMENT AND IMPLEMENTATION}

A multi-stakeholder team consisting of DFO, CFUG, and Project representatives was formed to initiate the LIP. The team selected 27 CFUGs from four "corridors," or bounded working areas in the Project districts: Kabhrepalanchok and Sindhupalchok. Selection criteria included the availability of resources, the composition of users, the activeness and interest of the CFUG, the size of the forest area and the number of user households. The last of the criteria, location, was determined by analyzing the site's accessibility, remoteness and agro-ecological diversity. Depending on the total number of user households, each CFUG selected four or five people, representing a cross-section of the CFUG members (including women, the poor, dalit, janajati, the elite and the CFUG committee), to serve as facilitators in the LIP process. Altogether 110 individuals (45 women and 65 men, 4 of whom were dalits) were selected. 
Figure 1: Step followed in facilitating the Livelihood Improvement Process in CFUGs

Presentation of LIP to CF $\rightarrow$ stakeholders and line agencies to secure their commitment

\section{Selection of 6-8 CFUGS in} each corridor

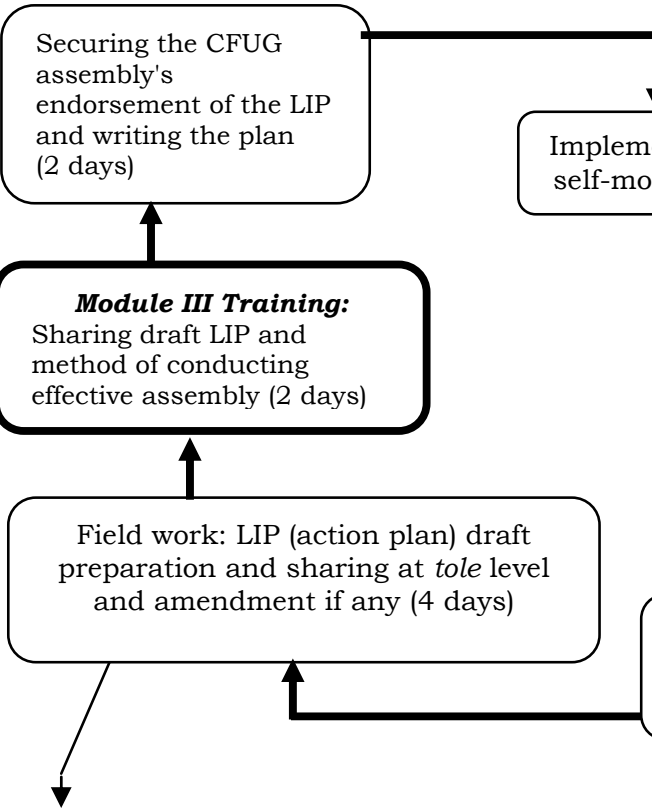

Action plan for livelihood improvement activities is prepared based on the needs and interests of different social groups and tole. The plan includes activities for CFUG governance reform, income generation, skills development, awareness raising/sensitisation,

mplementation of LIP and self-monitoring by CFUGs
Interactive workshop with selected CFUGs/CDGs on LIP concepts and process and commitment of CFUGs (1 day)
Selection of facilitators
by CFUGs

\section{Module-I Training:}

Orientation of facilitators in LIP

concepts, process, participatory

situation analysis and facilitation skills (3 days)

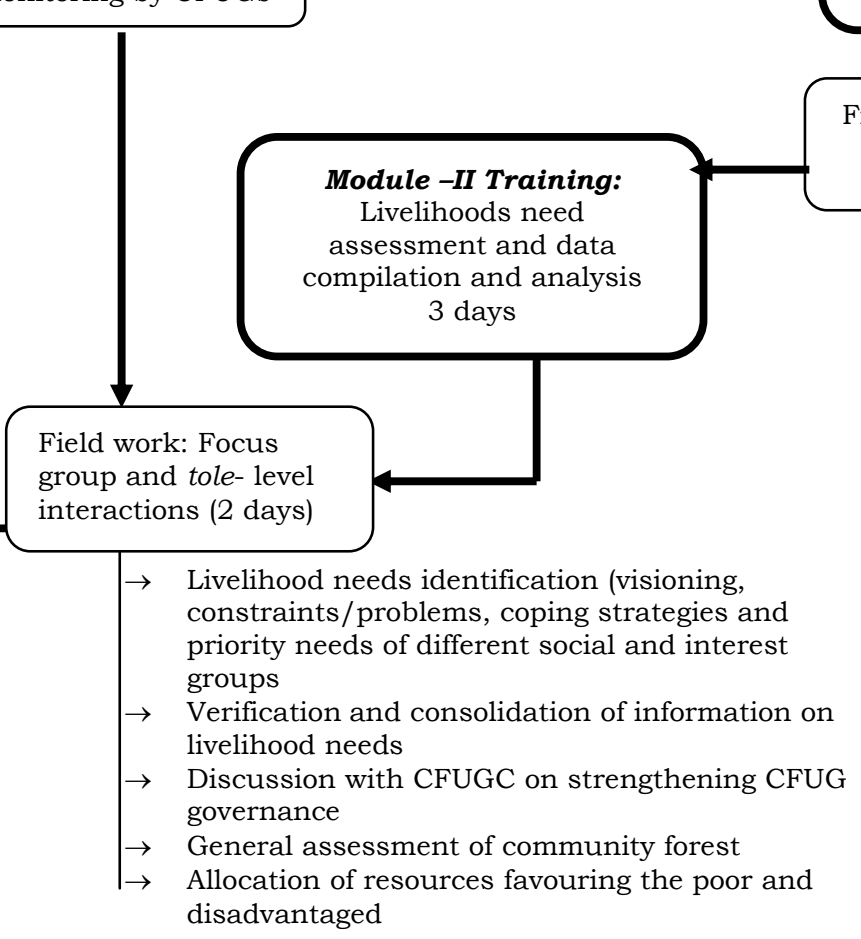

Field work: Participatory situation analysis in CFUG (2-3 days)

$\rightarrow \quad$ Meeting with CFUGC (livelihood concept and LIP process and preplanning)

$\rightarrow \quad$ Resource mapping

$\rightarrow$ Well-being ranking

$\rightarrow$ Interactions with key informants to identify major issues in and opportunities for the community

$\rightarrow$ HH-level interaction with poorest members to identify their livelihood needs/issues

$\rightarrow$ Institutional assessment

$\rightarrow$ Compilation, sharing and filing of findings

$\rightarrow$ Action plan for the activities to be imnlemented 
Those selected participated in an orientation for which the respective DFOs and the Project provided financial and technical support. Once trained, the facilitators volunteered their services to facilitate the LIP. After each field visit, Project and DFO staff shared their learning and incorporated these lessons into the planning process. The Project's key partner organisations (DFO, district-level line agencies, and FECOFUN) required hours of discussion and clarification to conceptualise and understand the LIP. The CF users had difficulty in making sufficient time for dialogue, often leading to delays in finalising the livelihood improvement plans.

The step-by-step process for facilitating a LIP is given in Figure 1. Factors considered in the process include the level of ownership of the CFUG; opportunities to build the capacity of users; empowerment of dalits, the poor, disadvantaged groups, and women; sensitisation of local elites and leaders; and review and reflection on learning.

\section{IMPACTS OF THE LIVELIHOOD IMPROVEMENT PROCESS}

\section{Sensitisation to and Awareness about Equity}

The LIP has made a striking impact on various actors, including CFUGs, elites, social workers, civil society, line agencies and Project staff, in terms of sensitising them to the social and governance issues of common property resource management at the local level. CFUG members, particularly the elites and CFUG committee members ${ }^{1}$, have realised the need for social inclusion and are helping to make CFUG plans that address the concerns of poor, dalit and women. LIP facilitators are actively involved in advocacy and awareness-raising about equity and participatory planning at the grassroots level. A LIP facilitator of Saparupa CFUG of Kavrepalanchok district expressed his understanding of equity as follows:

"I now understand what equity means in Community Forestry. Forest users and I used to think that equity meant sharing of resources equally among each CFUG households. Now I know that it actually means changing resource distribution systems from equal to unequal, with positive discrimination for marginalised groups. Now the landless, the poor, and other disadvantaged people have the opportunity to get more resources and benefits from CFUG programmes."

Likewise, LIP facilitators empower other CFUG members to voice their concerns at General Assembly and CFUG Executive Committee (CFUGC) meetings. An woman facilitator of Paleko Ban CFUG explains:

\footnotetext{
${ }^{1}$ The CFUG General Assembly elects an Executive
} Committee to implement its policies and activities.
"At first I didn't know about the activities of my CFUG and I was unable to sensitise other women in my village. Then I learned about the important role of women in community development processes at the LIP training. Now, I can sensitise other women and convince them to claim their rights to participate in forest resource management and to reap its benefits."

Increased Access to Resources and Benefits by Women and Disadvantaged Groups

One outcome of the LIP's sensitisation activities is that many more CFUGs are including equity provisions in their plans, particularly in terms of providing livelihood opportunities to the poor, to women and to disadvantaged groups. Lending CFUG funds for income generation schemes (goat and pig rearing, vegetable growing, etc.) for the poor and allocating patches of $\mathrm{CF}$ to women and the poor for forage development are two typical provisions. In Asetar Batase CFUG in Sindhupalchok, the CFUG committee members had this to say:

"We have included a provision to allocate land exclusively to women members to use for cultivating grasses and other trees like "lapsi". We accord priority to the poorest of the poor and to disadvantaged members. We have also established a "sal" leaf-plate making enterprise, in which the majority of the women in Asetar Batashe CFUG will be employed part-time."

The Women Empowerment Programme (WEP), another activity of the LIP, helps women to analyse how they could enhance their skills and knowledge and claim their rights to services, social processes and resources. As a result of the efforts of the WEP, a group of dalit women in Saparupa 
CFUG of Kabhrepalanchok now participate in decision-making. The women of Antarpu Salleni CFUG in Sindhuplachok have demonstrated that there is a greater potential to generate resources within and from themselves. For example, they raised funds by collecting grain from each household (one handful or muthi from each member or about one pathi (four kg.) grain of each season). They have already saved Rs 10,000, after deducting expenses. In addition to this, they have used part of the funds for the WEP literacy classes. Furthermore, their plan is to collect grain for 10 years and use the funds to improve the livelihoods of women.

Another positive change is the inclusion and support of disadvantaged groups in the CFUGs. For example, 71 dalit households were previously not included in the local CFUG have now been included and their right to access and use common property resources has been secured. The LIP also provides greater access to CFUG funds by disadvantaged groups to pursue incomegenerating activities. In Thuliban CFUG, for example, the committee allocated Rs 25,000 to five sarki ${ }^{2}$ households to raise pigs. When one farmer fell ill, the CFUG and the committee members gave him an extension for repaying his loan. In part through this income-generating activity, the Sarkis have been empowered to set a group agenda for discussion at CFUG assemblies.

The sense of ownership among disadvantaged groups and women has increased because the LIP addresses their concerns. In addition, CFUGs have provided the marginalised with opportunities to participate in training modules and study tours.

\section{Institutional Linkages and Building Social Capital}

The LIP has increased the social and institutional relations between CFUGs members and neighbouring CFUGs, government organisations, and NGOs. They approach district-level governmental and non-governmental organisations for service provision and resources, frequently securing them. Bhaluban CFUG of Sindhupalchok, for instance, got financial support for a small irrigation scheme and two women's groups in Sungure CFUG received support from the District Agriculture Development Office, Sindhupalchok. They received Rs. 3,200 each for vegetable farming. Utthan, an NGO working in the vicinity of Jangare CFUG, was persuaded to provide support to send marginalised Majhi children to school and to establish a clean drinking water supply scheme.

\section{Improvement in the Governance of CFUGs}

The LIP process encourages transparent, participatory, responsive and accountable governance. LIP facilitators, particularly women and the disadvantaged, have been able to make funds transparent to all members and to advocate the mobilisation of funds for income-generating programmes for poor households. One facilitator, representing a disadvantaged group in Chitrebatule Pakha CFUG, Kabhrepalanchok, was able to recover Rs. 25,000 that the treasurer and chairperson had misappropriated. The chairperson of Saparupa CFUG was also forced to make accounts public due to the insistence of facilitators. The CFUG then decided to use the funds only for providing the poor with productive loans. Sugure CFUG elected a new Executive Committee after the first violated the CFUG Constitution and Operational Plan. That CFUG recently lent Rs. 80,000 to 47 poor households, a large expansion of their initial effort: loans to just five households.

\section{CHALLENGES FACED AND LESSONS LEARNT}

Shifting the Project's approach from making tangible contributions like drinking water, schools, and seedlings to empowering communities and CFUGs by building their capacity to mobilise community resources was greeted with opposition from different levels. When training modules were conducted, for example, elite facilitators put pressure on women, the poor, and the disadvantaged to request that the project

\footnotetext{
2 Sarki is one of the dalit castes who are known as shoemakers.
} 
should provide incentives, such as daily allowances and logistic support, for the fieldwork associated with the process. Some elite persons objected to having to participate with women and disadvantaged trainees.

Conveying the idea that the LIP improves governance and enhances rural livelihoods took tremendous effort and time. This programme is expected to bring about changes in the attitudes, perceptions and knowledge of CFUG members, but achieving such pervasive social change is not a shortterm process. The proportion of poor and disadvantaged facilitators, for example, remained low, despite the efforts of Project staff. Because training modules had no provisions for daily allowances, participation put an economic strain on these groups, as they earned no money to feed their families on training days. They also found it difficult to make time to carry out volunteer work. Dalle BK of Asetar Batase CFUG voiced the following complaint at a Project workshop:

"I participated in this training without any extra allowances. I have not gotten enough to eat, as I have children and a wife at home who have remained hungry for the duration of this training. I am the only breadwinner in my family. I cannot participate in any more workshops or trainings in the future. Who will feed my family? (Dalle BK, Personal communication, 2005)."

Another problem identified was that the cooperation and coordination between facilitators and committee members is weak in many CFUGs. In addition, some facilitators felt uncomfortable conducting a well-being assessment. Only the most capable were successful, often by conducting the exercise informally. In general, categorising CFUG members into different economic classes in order to identify the poor threatened the rich and humiliated the poor. Moreover, the process falsely raised the expectations of the poorest of the poor that the Project would provide them with financial support.
It was difficult for local people to internalise the concept of the LIP as a tool for addressing social equity in Community Forestry. In fact, Project professionals found it challenging to convince not only the local facilitators, but also its own staff, who saw the LIP process as extra burden on top of Operational Plan (OP) preparation. They doubted that the LIP would be effective, as developing one takes time and it does not yield immediate impacts. Elites were also dubious: they questioned the ability of women, the poor and the disadvantaged to be involved in LIP effectively, as it appeared to be a time-consuming process that did not provide immediate benefit to the poor.

Despite the problems encountered in its development and implementation, a number of "best practices" were evolved and established. Many CFUGs practiced positive discrimination in order to address inequity, such as in providing concessions on the prices of forest products, lending CFUG funds at low interest rates for incomegenerating activities, providing scholarships to poor girls, and allocating some patches of community forest to poor households for forage and grass cultivation. CFUGs have improved their governance by organising regular committee meetings and increased the sense of ownership among members. Women, dalit and other disadvantaged groups are increasingly being included in the decision-making process by making a provision of including women in the CFUG committee (at a rate of 50 percent) and including proportionate representation of dalit and other disadvantaged groups. The decisions of Saparupa CFUG in Kabhrepalanchok to invite previously ostracised dalits to join and to allocate funds to the poor for goat-rearing were exemplary.

The CFUGs that implemented LIPs have expanded their relationships with governmental organisations beyond their established connection with DFOs. The success of Sungure and Bhaluban CFUGs in securing financial support from District Agriculture Office was noteworthy.

\section{CONCLUSION AND FUTURE IMPLICATIONS}

Community Forestry in the project districts has a great potential for contributing to poverty reduction and improving the livelihoods of local people. The LIP appears to be an appropriate tool for reaching the poor, as it helps to sensitise and inform all actors about the need of pro-poor and inclusive development process. Making local 
elites and power holders adopt pro-poor and gender-sensitive perspectives will require continuous informal interactions to reinforce the concepts and practices introduced through the LIP. Preparation and or revision of the Constitutions of CFUGs and their Operational Plans for forest management are the major activities that facilitate the Livelihood Improvement Process. The Constitutions and Operational Plans prepared by the active engagement of the people themselves address their needs and interests.

Local facilitators are key persons in facilitating the LIP. They must have sufficient conceptual understanding and knowledge about the strategic approach of the process. Individuals from disadvantaged groups should be given the opportunity to work as the facilitators. An informal method for identifying poor and marginalised groups or individuals in CFUGs needs to be developed to prevent people from feeling humiliated. Direct classification of users into affluent and poor groups appeared to be demoralising for the poor. The potential social fragmentation that could result within a CFUG could be avoided if the well-being ranking process is done cautiously, drawing upon the knowledge of village leaders and opinion setters and observing certain household indicators.

Sensitisation to the pro-poor livelihood approach is necessary at macro (policy), meso (implementing agencies, such as DFO) and micro (local) levels. DFOs, who implement the Community Forestry Programme on the ground, especially need to reflect a great deal more on the pro-poor and inclusive practices to institutionalise them, as the process depends largely on their personal attitudes, power relations, and application of the rule of law.

The opportunity cost to the users, especially of the poor and marginalised who are involved in the LIP, must be considered. The CFUGs could allocate fund to provide the poorest members with an incentive for their participation, covering their living expenses for that particular day of participation in the LIP.

\section{ACNOWLEDGEMENT}

We acknowledge the work of Manohara Khadka, Sangita Khadka, Manohar Lal Shrestha and Frans Arentz on the Livelihood Improvement Process in Nepal Australia Community Resource Management and Livelihood Project (NACRMLP), upon which we have drawn in writing this article. We also acknowledge the contribution of Kalpana Ghimire for her comments and suggestions on the draft of this paper. Our special thanks go to Michael Hawkes and Anthony Willett for their encouragement and help in writing this article. We appreciate the contribution made by Perry Thapa in editing this article.

\section{REFERENCES}

DFID and The World Bank. 2005. Unequal Citizens: Gender, Caste and Ethnic Exclusion in Nepal. Kathmandu: DFID/WB.

HMGN. 2002. The Tenth Plan (2002-2007), Kathmandu, Nepal: National Planning Commission.

Kane1, K. R. 2004. Twenty Five Years of Community Forestry: Contribution to Millennium Development Goals. In Twenty Five Years of Community Forestry: Proceedings of the Fourth National Workshop on Community Forestry, (pp. 4-18). Kathmandu: Community Forestry Division, Department of Forest.
NACRMLP. 2004. LIP Process Review Workshop Report (in Nepali). Tuki Prepared by Manohara Khadka and Parbati Nepali. Kathmandu: NACRMLP.

Pokharel, B.K. 2001. Community Forestry and People's Livelihoods. Forest and Livelihood, 1(1): 16-18.

Timsina, N. P.; Luintel, H.; Bhandari, K. and Thapalia, A. 2004. Action and Learning: An Approach for Facilitating a Change in Knowledge and Power Relationship in Community Forestry. Forest and Livelihood, 4 (1): 5-12. 